\section{(2) OPEN ACCESS}

- Additional material is published online only. To view please visit the journal online (http://dx.doi.org/10.1136/ jmedgenet-2019-106132).

For numbered affiliations see end of article.

\section{Correspondence to} Professor Han-Wook Yoo, Seoul, Korea (the Republic of); hwyoo@amc.seoul.kr Professor Beom Hee Lee; bhlee@amc.seoul.kr

Y-MK and M-SY contributed equally.

BHL and H-WY contributed equally.

Received 6 March 2019 Revised 27 August 2019 Accepted 14 September 2019 Published Online First 24 October 2019

\title{
Pharmacologic properties of high-dose ambroxol in four patients with Gaucher disease and myoclonic epilepsy
}

\author{
Yoon-Myung Kim, ${ }_{1}^{1}$ Mi-Sun Yum, ${ }^{2}$ Sun Hee Heo, ${ }^{3}$ Taeho Kim, ${ }^{3}$ Hee Kyung Jin, ${ }^{4}$ \\ Jae-sung Bae, ${ }^{5}$ Go Hun Seo, ${ }^{2}$ Arum Oh, ${ }^{2}$ Hee Mang Yoon, ${ }^{6}$ Hyun Taek Lim, ${ }^{7}$ \\ Hyo-Won Kim, ${ }^{8}$ Tae-Sung Ko, $^{2}$ Hyeong-Seok Lim, ${ }^{9}$ Mark J Osborn, ${ }_{10}$ Jakub Tolar, ${ }^{10}$ \\ Claudia Cozma, ${ }^{11}$ Arndt Rolfs, ${ }^{11,12}$ Ari Zimran, ${ }^{13}$ Beom Hee Lee, ${ }^{2,14}$ \\ Han-Wook Yoo (D) 2,14
}

\section{ABSTRACT \\ Background Ambroxol (ABX) has been suggested as an augmentative pharmacological agent for neuronopathic Gaucher disease (nGD). This study assessed the long-term safety and efficacy of combined therapy with high-dose $A B X$ and enzyme replacement therapy (ERT) in $\mathrm{nGD}$. \\ Methods $A B X+E R T$ therapy was administered for 4.5} years in four patients with $n G D$. ABX was initiated at a dose of $1.5 \mathrm{mg} / \mathrm{kg} / \mathrm{day}$, and the dose was escalated up to $27 \mathrm{mg} /$ $\mathrm{kg} /$ day. The target plasma level was $10 \mu \mathrm{mol} / \mathrm{L}$ or less. The changes in glucocerebrosidase activity, biochemical, safety and neurocognitive findings were assessed.

Results Enhanced residual GCcase activity was observed in all patients, as evidenced in both in vitro and in vivo studies. During the first 2 years of study with $A B X$ (up to $21 \mathrm{mg} / \mathrm{kg} /$ day), mean seizure frequencies and neurocognitive function worsened. After $A B X$ dosage was increased up to $27 \mathrm{mg} / \mathrm{kg} /$ day of $A B X$, its trough plasma concentration was 3.2-8.8 $\mu \mathrm{mol} / \mathrm{L}$. Drug-todrug interaction, especially with antiepileptic drug significantly affected the pharmacokinetic parameters of $A B X$. Importantly, at $27 \mathrm{mg} / \mathrm{kg} /$ day of $A B X$, the seizure frequencies markedly decreased from the baseline, and the neurocognitive function was improved. In addition, Lyso-Gb1, a biomarker for the severity and progression of $G D$, was normalised in all patients. High-dose ABX was well-tolerated with no severe adverse events.

Conclusions Long-term treatment with high-dose ABX+ERT was safe and might help to arrest the progression of the neurological manifestations in GD.

\section{INTRODUCTION}

Gaucher disease (GD; MIM230800) is a lysosomal storage disease caused by glucocerebrosidase (GCase) deficiency. Undegraded substrates, including glucosylceramide (Gb1), its deacylated form (glucosylsphingosine or lyso-Gb1) and other glycolipids, accumulate in the monocyte/macrophage lineage of the reticuloendothelial system, such as the liver, spleen and bone marrow. Accumulation also occurs in the central nervous system (CNS) in some patients causing progressive neurological manifestations, resulting in neuronopathic GD (nGD). ${ }^{12}$
Enzyme replacement therapy (ERT) and substrate reduction therapy (SRT) could achieve significant improvement in the systemic manifestations, including haematological, visceral and skeletal manifestations. ${ }^{34}$ Unfortunately, recombinant enzymes do not cross the blood-brain barrier (BBB) and therefore do not impact on the CNS. The situation with the SRT available today is that both miglustat (despite crossing the $\mathrm{BBB}$ ) and eliglustat (which is pumped out across the BBB) do not affect the CNS features of nGD, nevertheless-this modality, using different formulations, can lead to changes in $\mathrm{nGD}$, but at present there is only one drug in early phases of clinical trials (venglustat). ${ }^{4-6}$

Pharmacological chaperones enable the defective enzyme to fold in a manner that restores partial enzyme activity within the lysosome. A well-known mucolytic agent, ambroxol (ABX) has been identified as a pharmacological GCase chaperone, ${ }^{7-10}$ and six GCase mutant proteins, such as p.Asn227Ser (NP_000148.2) (traditional numbering, ${ }^{11}$ p.Asn188Ser), p.Phe252Ile (p.Phe213Ile), Gly232Trp (p.Gly193Trp), Arg159Trp (p.Arg120Trp), Gly241Arg (p.Gly202Arg) and Asn409Ser (p.Asn370Ser) have been shown to be responsive to $\mathrm{ABX}$ at concentrations of $0.3-30 \mu \mathrm{mol} / \mathrm{L} .^{10}{ }^{12}$ Importantly, ABX crosses the $\mathrm{BBB}$ and therefore may represent a strategy for mediating therapeutic benefit in the central nervous system. ${ }^{101314}$ Indeed, previous studies have shown promising results using high-dose $\mathrm{ABX}$ in GD. The first study with nGD patients was published by Narita $e t a l^{10}$ in 2016 which tried to verify the effects of $\mathrm{ABX}$ in five $\mathrm{GGD}$ patients; however, there still remain many uncertainties regarding its longterm safety and efficacy. ${ }^{10} 15$

In this study, we aimed to investigate the longterm clinical safety and efficacy of combined therapy of high-dose ABX+ERT on the neurological manifestations in patients with nGD.

\section{METHODS}

\section{Study design}

This study was a single-centre study performed at the Asan Medical Center, Seoul, Korea from August 2013 to April 2018. The study protocol 
was registered at the Clinical Research Information Service, Korea Centers for Disease Control and Prevention, Ministry of Health and Welfare (Republic of Korea) (no. KCT0003218). The detailed information of this study can be found in Clinical Research Information Service (https://cris.nih.go.kr/cris/en/ search/search_result_st01.jsp?seq=12387).

The study period was 4.5 years. Four patients (Pt1-4) with nGD were included, and Pt1 and Pt2 were siblings. The baseline clinical characteristics and neurological manifestations of the patients are summarised in table 1. All patients had been treated for 4-14 years with ERT before enrolment (imiglucerase, $60 \mathrm{IU} / \mathrm{kg}$ q 2 weeks). ERT dosage was maintained as Abcertin (ISU Abxis, Seongnam, Korea) throughout the study period in all patients. Oral ABX HCl (Mucopect $30 \mathrm{mg}$; Boehringer Ingelheim, Ingelheim am Rhein, Germany) was administered daily as three divided doses. ABX was started at a dose of $1.5 \mathrm{mg} / \mathrm{kg} /$ day, and the dose was escalated every one or 2 months by $3 \mathrm{mg} / \mathrm{kg} / \mathrm{day}$ up to $21 \mathrm{mg} / \mathrm{kg}$ /day or a maximum daily dose of $990 \mathrm{mg}$ until the trough plasma concentration of $\mathrm{ABX}$ was $10 \mu \mathrm{mol} / \mathrm{L}$ or less. The trough plasma concentration of $\mathrm{ABX}$ was measured three times before increasing its dosage. In addition, cerebrospinal fluid (CSF) ABX concentration was measured when a patient received $21 \mathrm{mg} / \mathrm{kg} / \mathrm{day}$ of $\mathrm{ABX}$ and whenever the dose was escalated. The dosage of $21 \mathrm{mg} / \mathrm{kg} /$ day was maintained for 1.5 years and then it was increased up to $1390 \mathrm{mg} /$ day or $27 \mathrm{mg} / \mathrm{kg} /$ day and maintained for other 2 years to reach high ABX plasma concentration (10 $\mu \mathrm{mol} / \mathrm{L}$ or less).

\section{Efficacy assessment}

The primary endpoint in our study was to evaluate the improvement in residual GCase activity in peripheral leukocytes. GCase activity was measured immediately before ERT administration.

Secondary endpoints were the biochemical and clinical outcomes of each patient after the conclusion of the study. Biochemical profiles, such as chitotriosidase, angiotensinconverting enzyme, haemoglobin and platelet count, were measured every 6 months. The frequency of seizures, requirement for antiepileptic drugs, and changes in saccadic eye movement were recorded. The modified severity scoring tool (mSST) and Korean Wechsler adult intelligence scale-IV (K-WAIS) were measured every 6-12 months. The Korean version of modified Barthel index (K-MBI) was measured every 2-2.5 years. Brain magnetic resonance spectroscopy (MRS) was performed every year to evaluate the changes in the metabolite values of $\mathrm{N}$-acetylaspartate/creatine $(\mathrm{NAA} / \mathrm{Cr})$ and choline/creatine $(\mathrm{Cho} / \mathrm{Cr})$ in the frontal white matter and occipital cortex that are known to be affected in nGD. ${ }^{16}{ }^{17}$ We also examined the metabolite of the basal ganglia and cerebellum (dentate nucleus), the areas that control exercise and equilibrium functions and where storage cell accumulation has been identified as well. ${ }^{18}$ Lyso-Gb1 level was also measured in dried blood spots, plasma and CSF, as previously described. ${ }^{19-21}$ Bone densitometry was performed every year to measure bone density of the lumbar spine and femur neck. Chest X-ray was taken at baseline study and none of the patients had interstitial lung involvement of GD which shows resistance to ERT.

\section{Safety assessment}

All adverse events, including clinically significant abnormal findings in the laboratory data, regardless of the severity, were documented and graded using the NCI Common Toxicity Criteria version 4 , and it was determined if the adverse event was related to the medical treatment.

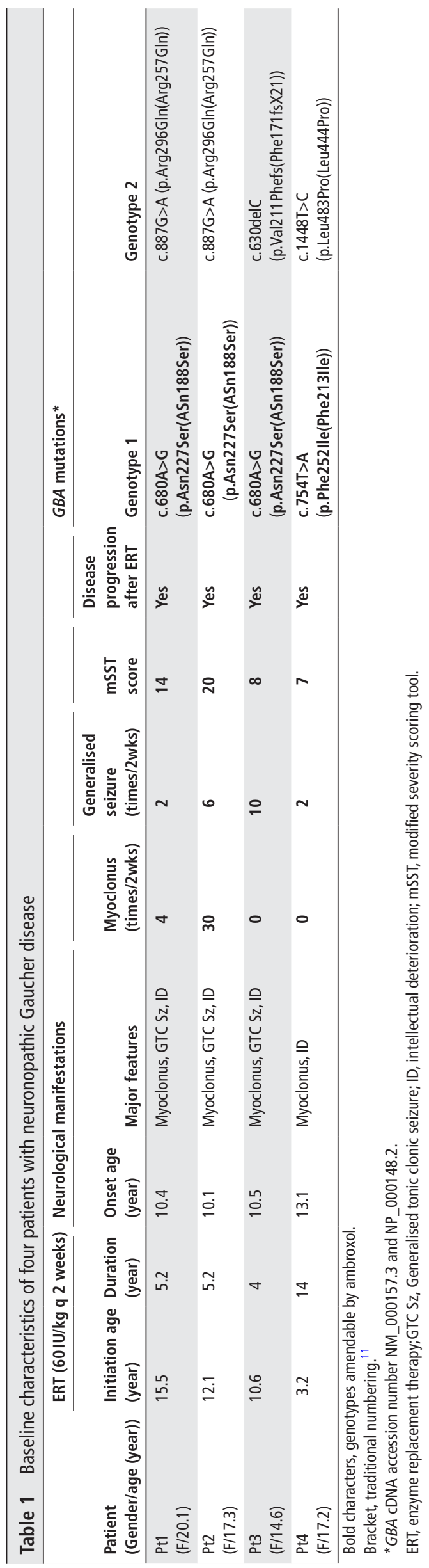




\section{Pharmacokinetic (PK) assessment}

Blood samples for PK analysis were drawn when the patients received $27 \mathrm{mg} / \mathrm{kg} /$ day $\mathrm{ABX}$, before the first $\mathrm{ABX}(450 \mathrm{mg})$ dose (0, pre-dose), and at $0.5,1,1.5,2,3,4,5$ (the second dose), $6,7,8$ and 9 hours after the first dose. The serum concentrations were measured by a validated liquid chromatography tandem-mass spectrometry. ${ }^{22}$ PK of ABX was analysed by a non-compartmental method using WinNonlin software V.6.3 (Pharsight Co, Princeton, New Jersey, USA). The analysis was based on actual sampling time. The peak plasma concentration $\left(\mathrm{C}_{\max }\right)$ and the time taken to reach $\mathrm{C}_{\max }\left(\mathrm{T}_{\max }\right)$ were determined from observed values. The terminal elimination rate constant $\left(\lambda_{\mathrm{z}}\right)$ was estimated by linear regression of the terminal log-linear portion of the serum concentration-time curves. The terminal elimination half-life $\left(t_{1 / 2 \beta}\right)$ for each patient was calculated as $\ln (2) / \lambda_{\mathrm{z}}$. The area under the serum concentration-time curve (AUC) from time of dosing to 4 hour $\left(\mathrm{AUC}_{0-4 \mathrm{~h}}\right)$ was calculated by the trapezoidal rule. Based on the AUC and $\lambda_{z}$, apparent total clearance $(\mathrm{CL} / \mathrm{F})$ and terminal volume of distribution $\left(\mathrm{V}_{\mathrm{z}} / \mathrm{F}\right)$, was calculated.

\section{In vivo and in vitro biochemical assays of GCase activity}

The GBA (NM_000157) human cDNA clone was obtained (SC120080 OriGene, Rockville, Maryland, USA) and mutant GBA constructs were generated using the PCR-based DpnItreatment site-directed mutagenesis method. Transient transfection was performed according to the manufacturer's instructions using Effectene transfection reagent \#301427 (Qiagen, Hilden, Germany). Control primary fibroblasts were obtained from healthy volunteers. GCase enzyme activity assay was performed using a standard fluorometric method.

Fluorescence was detected using a fluorescence spectrophotometer (Molecular devices, San Jose, California, United States). To detect GCcase localisation and cell death and aggresome formation by $\mathrm{ABX}$, control and GD fibroblasts were cultured with or without $10 \mu \mathrm{mol} / \mathrm{L} \mathrm{ABX}$ for 5 days. Anti-GCase antibody, MAB7410 (R\&D systems, Minneapolis, Minnesota, United States) was added and then LAMP1 antibody, ab24170 (Abcam, Cambridge, UK) was used for lysosome identification. The fluorescent images were acquired using a confocal microscope LSM 780 (ZEISS, Oberkochen, Germany). Aggresome staining was performed according to the manufacturer's manual (aggresome detection kit; Abcam; ab139486). Positive control cells were treated with $5 \mu \mathrm{mol} / \mathrm{L} \mathrm{MG} 132$ for 18 hours. The anti-GCcase antibody (MAB7410) solution was added after staining with the aggresome detection reagent and then the dish was incubated for an appropriate time at dark. The fluorescent images were acquired using a confocal microscope LSM 880 (ZEISS, Oberkochen, Germany). Cell viability was measured by cell counting kit-8 (CCK-8; DOJINDO, CK04, Japan), and cytotoxicity was measured by LDH (lactate dehydrogenase) cytotoxicity detection kit (TAKARA, MK401, Japan). For controls, Triton X-100 (positive control) and untreated normal cells (negative control) were used, and the medium was used for background.

\section{RESULTS}

\section{Evidence of enhanced GCase activity by $A B X$ in vitro}

The GBA mutations identified in the four patients (Pt1-4) were p.Val211Phefs (traditional numbering, ${ }^{11}$ Phe171fsX21), p.Asn227Ser (Asn188Ser), p.Phe252Ile (Phe213Ile), p.Arg296Gln (Arg257Gln) and p.Leu483Pro (Leu444Pro).

COS7 cells were transfected with GBA-WT (wild type), p.Asn227Ser, p.Phe252Ile, p.Arg296Gln and p.Leu483Pro DNA
A
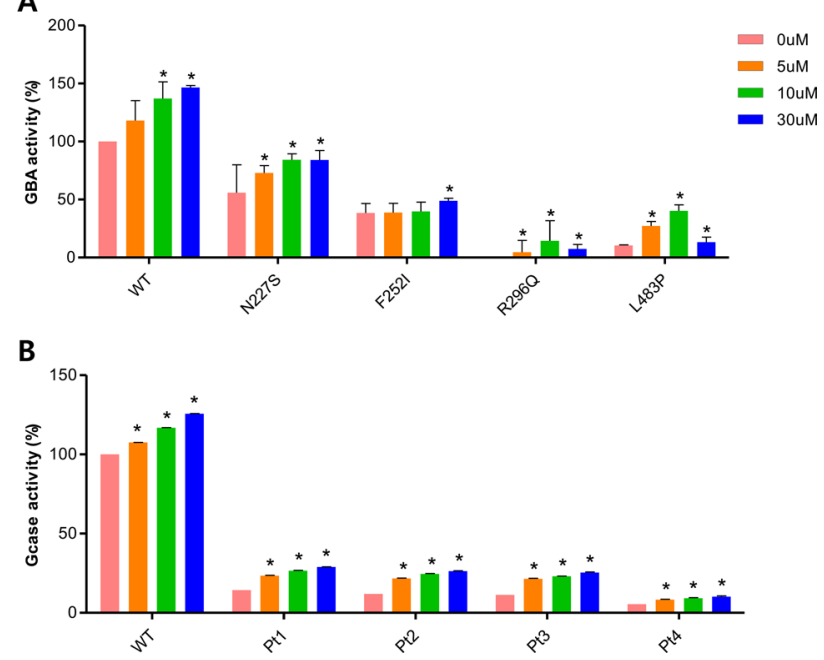

Figure 1 (A) Glucocerebrosidase (GCcase) activity was measured in COS7 cells transfected with GBA-WT, p.Asn227Ser (traditional numbering, ${ }^{11}$ Asn188Ser), p.Phe252lle (Phe213lle), p.Arg296GIn(Arg257GIn) and p.Leu483Pro (Leu444Pro) at different concentration of ambroxol $(0,5$, 10 and $30 \mu \mathrm{mol} / \mathrm{L}$ ) for 2 days. (B) GCcase activity was measured in the fibroblasts of four patients with neuropathic Gaucher disease (Pt1-4) at different concentrations of ambroxol $(0,5,10$ and $30 \mu \mathrm{mol} / \mathrm{L})$ for 5 days. ${ }^{*} \mathrm{GC}$ case activity significantly increased with the increase in ambroxol concentration ( $p<0.05$, compared with the baseline).

and cultured with varying concentrations of $\mathrm{ABX}(0,5,10$ and $30 \mu \mathrm{mol} / \mathrm{L}$ ) for 2 days.

The residual GCase activity of COS7 cells was significantly enhanced with the increase in $\mathrm{ABX}$ concentration, not only in the cells expressing ABX-amendable GBA mutants (p.Asn227Ser and p.Phe252Ile) but also in those expressing p.Arg296Gln and p.Leu483Pro which are unknown GBA variants for ABX responsiveness (figure 1A). Conversely, GCase activity decreased in the cells overexpressing two GBA mutants, p.Arg296Gln and p.Leu483Pro, in the presence of $30 \mu \mathrm{mol} / \mathrm{L} \mathrm{ABX}$.

Moreover, ABX resulted in a significant enhancement of the residual GCase activity in fibroblasts derived from the four patients (Pt1-4) at different concentrations of $\mathrm{ABX}(0,5,10$ and $30 \mu \mathrm{mol} / \mathrm{L}$ ) for 5 days (figure $1 \mathrm{~B}$ ). Using confocal microscopy, a focal localisation of GCase in the lysosomes was observed in the fibroblasts of Pt1-4 treated with $10 \mu \mathrm{mol} / \mathrm{L} \mathrm{ABX}$ for 5 days (online supplementary figure I), and GCase was not colocalised with aggresome in the juxtanuclear areas (online supplementary figure II). In addition, cytotoxicity was not observed in WT and GD fibroblast cells at $10 \mu \mathrm{mol} / \mathrm{L}$ of $\mathrm{ABX}$, which was assessed by LDH and CCK-8 assays (online supplementary figure III).

\section{Evidence of enhanced GCase activity by $A B X$ in vivo}

All patients (Pt1-4) completed the study. Dose escalation was uneventful except in one patient $(\mathrm{Pt} 2)$, who experienced respiratory difficulty owing to a significant increase in mucus production (online supplementary figure IV). During the first year, the $\mathrm{ABX}$ dose was increased by $3 \mathrm{mg} / \mathrm{kg} /$ day every $1-2$ months up to $21 \mathrm{mg} / \mathrm{kg} /$ day or $990 \mathrm{mg} /$ day. The maximum $\mathrm{ABX}$ dose was determined based on previous clinical studies using $1000 \mathrm{mg} /$ day. $^{2324}$

At a dose of $21 \mathrm{mg} / \mathrm{kg} / \mathrm{day}$, the trough plasma concentration of $\mathrm{ABX}$ was $2.3-5.7 \mu \mathrm{mol} / \mathrm{L}$, and the CSF concentration was $0.3-1.4 \mu \mathrm{mol} / \mathrm{L}$. After maintaining this dose for 1.5 years, the ABX dose was escalated up to $27 \mathrm{mg} / \mathrm{kg} /$ day. At this level, the 

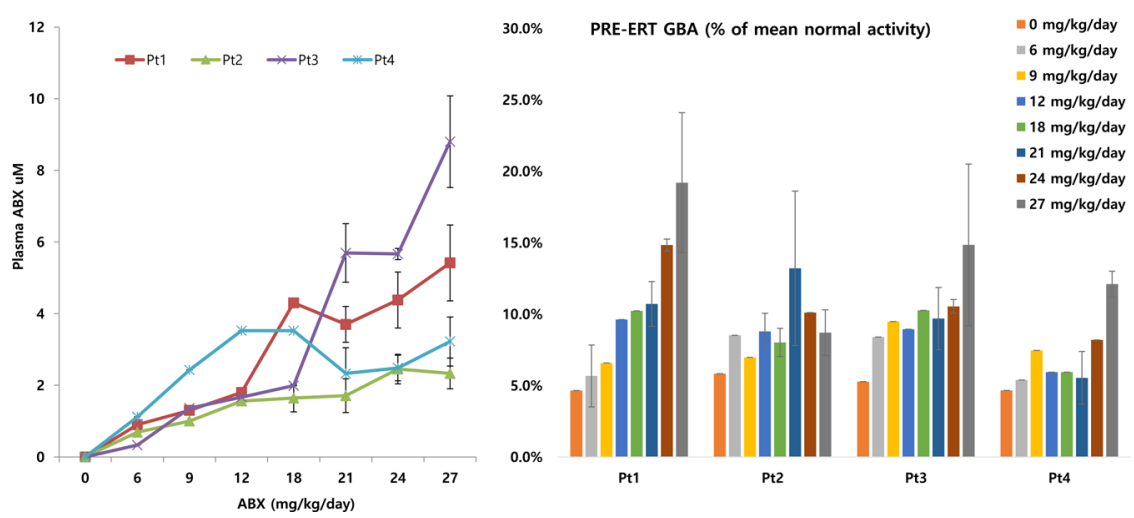

Figure 2 ABX plasma concentration along with the enhancement of residual glucocerebrosidase activity in four patients with neuronopathic Gaucher disease (Pt1-4) receiving combined treatment with high-dose ambroxol and ERT. ABX, ambroxol; ERT, enzyme replacement therapy.

trough plasma concentration of $\mathrm{ABX}$ was 3.2-8.8 $\mu \mathrm{mol} / \mathrm{L}$, whereas its CSF concentration was $0.6-1.9 \mu \mathrm{mol} / \mathrm{L}$. The CSF/ plasma concentration ratio was $21.2 \% \pm 2.9 \%$ (figure 2 and online supplementary figure IV).

The baseline pre-ERT GCase activity in peripheral leukocytes of Pt1-4 was $5.1 \pm 0.6$ (range, 4.7-5.8)\% of the mean normal activity (ref, $28.7 \pm 10.7 \mathrm{nmol} / \mathrm{h} / \mathrm{mg}$ ). At a dose of $21 \mathrm{mg} /$ $\mathrm{kg}$ /day ABX, GCase activity was $9.8 \pm 3.2(5.5-13.2) \%$ of the mean normal activity $(\mathrm{p}=0.042)$. GCase activity increased up to $13.7 \pm 4.4(8.7-19.2) \%$ of the mean normal activity at ABX dose of $27 \mathrm{mg} / \mathrm{kg} /$ day $(\mathrm{p}=0.020)$ (figure 2).

\section{Clinical outcomes of nGD after 4.5 years of high-dose $A B X+E R T$ treatment}

Biochemical and bone densitometry outcomes

After 4.5 years of high-dose ABX+ERT treatment, no significant change was observed in the haematological profile, such as haemoglobin content and platelet count (online supplementary figure V). All patients had undetectable chitotriosidase activity. The baseline ACE was 54.4 14.1 (33.4-62.6) IU/L, and $31.6 \pm 19.3(5-51) \mathrm{IU} / \mathrm{L}$ after 4.5 years. The baseline $\mathrm{Z}$-score of lumbar spine bone densitometry was $-0.8 \pm 1.3(-2.5$ to 0.5$)$, and $-0.5 \pm 1.6(-2.1$ to 1.7$)$ after 4.5 years. The baseline $\mathrm{Z}$-score of femoral neck bone densitometry was $-0.8 \pm 0.4(-1.2$ to $-0.2)$, and $-1.0 \pm 0.5(-1.6$ to -0.4$)$ after 4.5 years. There were no significant changes in bone densitometry findings during the 4.5 years (online supplementary table I).

\section{Neuropsychiatric outcomes}

The mSST score was measured to monitor the neurological progression of GD in each patient (online supplementary table II). At baseline, the mSST score was $12.3 \pm 6$ (7-20); however, it worsened after 2.5 years of high-dose ABX+ERT treatment $(15.1 \pm 6.2(9.5-21))$, and then improved after 4.5 years (12.4 \pm 5.3 (7-18.5)) (figure 3A). In Pt 1 and 2, improvement of swallowing and speech was noticeable. In addition, Pt 1 showed improvement in pyramidal and extrapyramidal symptoms. Pt 3 and 4 showed improvement of epilepsy and cerebellar tremor.

The K-MBI score was measured to evaluate daily life movement and performance ability. The mean K-MBI score was $66.3 \pm 36.2(33-100)$ at baseline. It diminished after 2.5 years $(51 \pm 32.7(24-88))$ and then improved after 4.5 years (71.8 \pm 30.6 (41-100)) (figure 3B). Major improvements were identified in the categories of feeding, dressing, transfer and mobility.

At baseline, the frequencies of myoclonic and generalised tonic-clonic (GTC) seizures were $8.5 \pm 14.5(0-40)$ times/2 weeks and $5 \pm 3.8(2-10)$ times/2 weeks, respectively. After 2.5 years, the number of myoclonic seizures decreased to $2 \pm 4(0-8)$ times/2 weeks; however, the frequency of GTC seizures was $22 \pm 30.2(0-64)$ times/2 weeks. After 4.5 years, myoclonic and GTC seizures markedly decreased to $1.25 \pm 2.5(0-5)$ times/2 weeks and $0.5 \pm 1(0-2)$ times/2 weeks, respectively. Meanwhile, the number of antiepileptic drugs also increased from $4.8 \pm 1.7$ (3-7) per patient at the baseline to $6.3 \pm 2.4(3-8)$ per patient after 4.5 years (figure 4 and online supplementary table III).
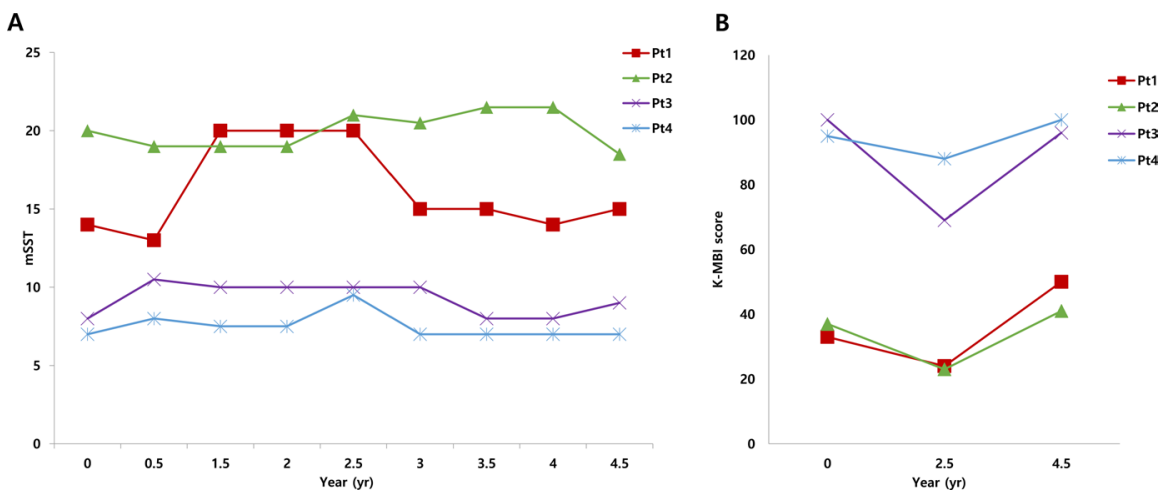

Figure 3 Changes in modified severity scoring tool (mSST) (A) and Korean version of modified Barthel index (K-MBI) (B) of four patients with neuronopathic Gaucher disease (Pt1-4) during 4.5 years of combined treatment with high-dose ambroxol and enzyme replacement therapy. 

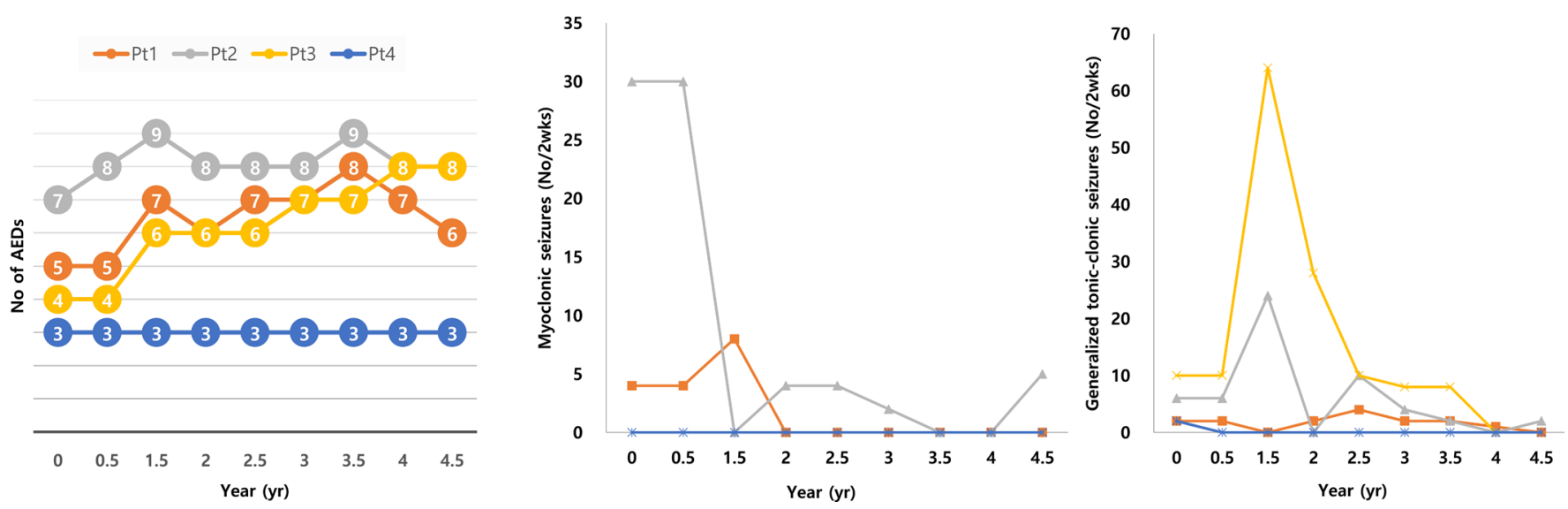

Figure 4 Changes in seizure frequency and number of antiepileptic drugs (AEDs) in four patients with neuronopathic Gaucher disease (Pt1-4) during 4.5 years of combined treatment with high-dose ambroxol and enzyme replacement therapy.

The K-WAIS score was analysed to evaluate the changes in intelligence. At baseline, the verbal comprehension index (VCI), perceptual reasoning index (PRI), working memory index (WMI), processing speed index (PSI) and full-scale intelligence quotient (FSIQ) were 65 \pm 6.8 (56-72), 55 10 (49-70), $60 \pm 6.6$

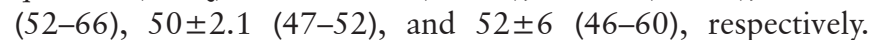
After 4.5 years of treatment, VCI, PRI, WMI, PSI and FSIQ were $66 \pm 7.4$ (57-74), $52 \pm 3.4$ (50-57), $53 \pm 3.5$ (50-58), $50 \pm 0$ (50-50) and 48 44.1 (44-53), respectively (online supplementary figure VI).

There was no improvement in horizontal and vertical saccadic eye movement after 4.5 years (online supplementary video). Importantly, it deteriorated in two patients (Pt1 and Pt2) and remained stationary in the other two patients ( $\mathrm{Pt} 3$ and $\mathrm{Pt} 4$ ). Standing and walking balance was maintained in Pt3 and Pt4 through the study period. In Pt1, it deteriorated until 2.5 years of study and then recovered during the next 2 years. In Pt2, no recovery was observed.

There were no significant changes in the metabolite values of $\mathrm{NAA} / \mathrm{Cr}$ and $\mathrm{Cho} / \mathrm{Cr}$ in the frontal white matter, basal ganglia, occipital cortex and cerebellum (dentate nucleus) as shown by brain MRS (online supplementary figure VII).

\section{Pharmacokinetics}

A PK analysis was carried out when all patients were receiving $27 \mathrm{mg} / \mathrm{kg} /$ day ABX or $450 \mathrm{mg}$ ABX three times daily.

The $\mathrm{C}_{\max }$ was $0.46 \pm 0.19 \quad(0.26-0.72) \mathrm{ng} / \mathrm{mL}, \mathrm{T}_{\max }$ was $1.13 \pm 0.48(0.5-1.5)$ hour, $\mathrm{AUC}_{0-4 \mathrm{~h}}$ was $1.68 \pm 0.73$ (0.962.68) hour*ng/mL, CL/F was $34.27 \times 10^{3} \pm 9.45 \times 10^{3}$ $\left(9.45 \times 10^{3}-200.14 \times 10^{3}\right) \mathrm{L} / \mathrm{h}, \mathrm{Vz} / \mathrm{F}$ was $1.08 \times 10^{6} \pm 0.49 \times 10^{6}$ $\left(0.6 \times 10^{6}-10.75 \times 10^{6}\right) \mathrm{L} / \mathrm{h}$, and $\mathrm{t}_{1 / 2 \beta}$ was $21.7 \pm 6.47(15.56-$ 30.8 ) hour (online supplementary figure VIII). Since a wide variation in the PK parameters was observed among patients, drug-drug interactions were assessed. ABX is metabolised by CYP3A4, ${ }^{25}$ and topiramate administered to Pt1, 2, 4 and carbamazepine administered to Pt2 are CYP3A4 inducers, whereas divalproate sodium administered to $\mathrm{Pt} 2,3$ is a weak CYP3A4 inhibitor. In particular, the $\mathrm{C}_{\max }$ and $\mathrm{AUC}_{0-4 \mathrm{~h}}$ in $\mathrm{Pt} 3$ were higher than those in Pt1, 2 and 4 (online supplementary figure VIII).

\section{Safety assessment}

High-dose ABX was generally safe and tolerable in all patients. Several drug-related side effects were observed (online supplementary table IV); however, they did not require drug discontinuation. Pt3 occasionally showed transient proteinuria ranging from 34 to $67.5 \mathrm{mg} /$ day. Mucus production significantly increased in Pt2, who complained of respiratory difficulty; thus, escalation of $\mathrm{ABX}$ dose was delayed in this patient. However, ABX dose was slowly escalated up to $27 \mathrm{mg} / \mathrm{kg} / \mathrm{day}$ in $\mathrm{Pt} 2$, and this dose was tolerable.

\section{Changes in Lyso-Gb1}

Lyso-Gb1 level was measured as a corollary for the severity and progression of GD. ${ }^{20}$ As the dose of ABX increased, plasma lysoGb1 level decreased in all patients (figure 5).

Lyso-Gb1 was also measured in dried blood spots from nine non-nGD patients receiving ERT alone (30-60 IU/kg every other week) for $10.9 \pm 8.3$ years and from 3 nGD patients receiving ERT alone (60-120 IU/kg every other week) for 4-24 years. Lyso-Gb1 level was 93.8 $468.4(27-115)$ and $45.7 \pm 19.8$ (25.777.2) $\mathrm{ng} / \mathrm{mL}$ in the non-nGD and nGD patients, respectively. At $\mathrm{ABX}$ dose of $27 \mathrm{mg} / \mathrm{kg} /$ day, lyso-Gb1 level in the dried blood spots of Pt1-4 was $7.7 \pm 1.8(6.5-10.3) \mathrm{ng} / \mathrm{mL}$ (ref, $<4.8 \mathrm{ng} / \mathrm{mL}$ ), which was significantly lower than that in non-nGD and nGD patients without $\mathrm{ABX}$ treatment (Mann-Whitney test, $\mathrm{p}<0.01$ ) (figure 5). At ABX dose of $27 \mathrm{mg} / \mathrm{kg} /$ day, CSF Lyso-GB1 level was $0.52 \pm 0.04 \mathrm{ng} / \mathrm{mL}(9.2 \% \pm 2.5 \%$ of plasma Lyso-Gb1).

\section{DISCUSSION}

Long-term treatment with high-dose $\mathrm{ABX}+\mathrm{ERT}$ was tolerable in all patients during the study duration (4.5 years). Asymptomatic mild proteinuria and increased respiratory mucus production were the only major related adverse reactions. Since the degree of proteinuria is related to renal function, a careful follow-up is required for monitoring proteinuria and renal function. Importantly, the increase in respiratory mucus production was the major adverse event that hindered ABX dose escalation.

Importantly, our in vitro and in vivo data showed significant increases in GCase activity. In addition, an increase in the subcellular localisation of lysosomes was observed in patient-derived fibroblasts treated with $10 \mu \mathrm{mol} / \mathrm{L} \mathrm{ABX}$, indicating that $\mathrm{ABX}$ facilitated its trafficking to the lysosomes.

In a previous study by Narita et al, high-dose ABX+ERT showed remarkable improvement in myoclonus, myoclonic seizures and pupillary light reflex dysfunction in five nGD patients despite the variation in the treatment period $(0.5-4$ years). ABX was administrated and escalated at the target dose of $25 \mathrm{mg} / \mathrm{kg} /$ day or a maximum dose of $1300 \mathrm{mg} /$ day. The frequency of myoclonic seizures decreased after increasing the dose of ABX to 9 or $15 \mathrm{mg} / \mathrm{kg} /$ day. Frequency of GTC seizures 


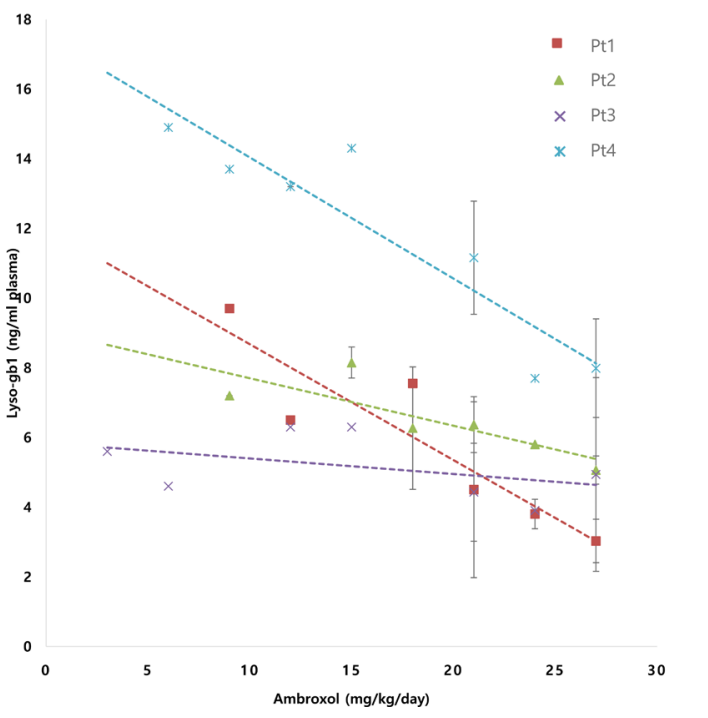

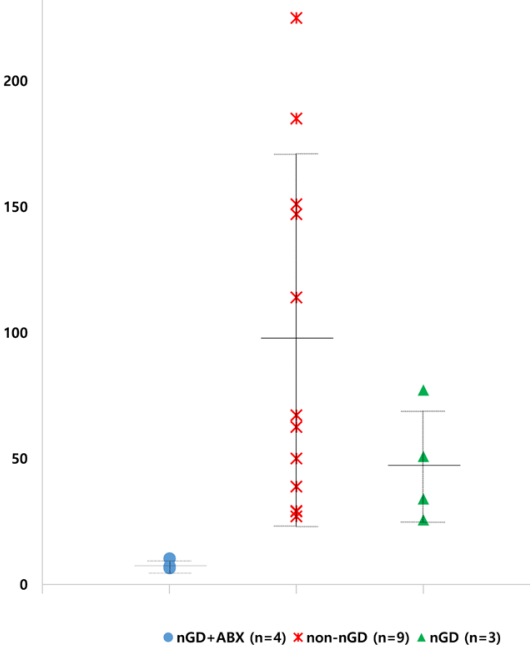

Figure 5 (A) Plasma Lyso-Gb1 levels in four patients with neuronopathic Gaucher disease (nGD) (Pt1-4) during 4.5 years of combined treatment with high-dose ambroxol and enzyme replacement therapy. Plasma glucosylsphingosine (lyso-Gb1) level of Pt1-4 receiving $27 \mathrm{mg} / \mathrm{kg} / \mathrm{day}$ ambroxol was $5.3 \pm 2.5$ $(2.4-11.6) \mathrm{ng} / \mathrm{mL}$. (B) The lyso-Gb1 level of Pt1-4 in the dried blood spots $(7.7 \pm 1.8(6.5-10.3) \mathrm{ng} / \mathrm{mL})$ was significantly lower than those of 9 non-nGD patients $(93.8 \pm 68.4(27-115) \mathrm{ng} / \mathrm{mL}) \mathrm{ng} / \mathrm{mL}$ and of $3 \mathrm{nGD}$ patients without ambroxol treatment $(45.7 \pm 19.8(25.7-77.2) \mathrm{ng} / \mathrm{mL})(\mathrm{ref} .,<4.8 \mathrm{ng} / \mathrm{mL})(\mathrm{p}<0.01)$.

did not change, but the duration of seizure or frequency of status epilepticus decreased in some patients. Moreover, two patients were able to walk again with an impressive recovery of gross motor function. ${ }^{10}$ However, during the first 2.5 years of our study, the neurological manifestations were not improved or in some cases aggravated, as evidenced from the mSST and K-MBI scores. Considering that all the patients in our study and that by Narita et al both harboured the ABX-amendable mutations, p.Asn227Ser or p.Phe252Ile, except in one patient in the study by Narita et al, the different pattern of response is not considered as related to $G B A$ mutation spectrum. In our study, because the dosage of $\mathrm{ABX}$ increased by $3 \mathrm{mg} / \mathrm{kg} /$ day every $1-2$ months, the natural progression of neurological manifestations might have not been delayed by the therapeutic effects of $\mathrm{ABX}$ during the early period of our study.

An improvement in the neurological manifestation was observed only after the dose of ABX increased up to $27 \mathrm{mg} / \mathrm{kg} /$ day during last 2 years of the study. The mSST and K-MBI scores were stabilised/maintained, and the neurocognitive function was sustained in all patients. In addition, seizure frequency markedly decreased. Although the number of antiepileptic drugs increased during our study, the remarkable prevention of seizures was meaningful clinically and in quality of life improvement.

The threshold enzyme activity to prevent substrate accumulation has been suggested to be $>10 \%-15 \%$ of normal. ${ }^{26}$ In our study, approximately 9\%-19\% of the mean normal GCase activity was achieved in patients who received $27 \mathrm{mg} / \mathrm{kg} / \mathrm{day}$ $\mathrm{ABX}$ (figure 2). Luan et al ${ }^{12}$ showed that GCase activity significantly increased in the brains of normal mice receiving $60 \mathrm{mg} /$ $\mathrm{kg}$ /day $\mathrm{ABX}$, which is equivalent to a human dose of $4.8 \mathrm{mg} /$ $\mathrm{kg} /$ day. ${ }^{27}$ However, the degree of improvement in brain GCase activity to avoid Gb1 and lyso-Gb1 accumulation is not known. In addition, it is noteworthy that since $\mathrm{ABX}$ acts as a chemical chaperone to GCase, it may also act as an inhibitor at high concentrations. ${ }^{8}$ In support of this, as shown in figure $1 \mathrm{~A}, \mathrm{ABX}$ acted as an inhibitor of some GCase mutants at concentrations of $30 \mu \mathrm{mol} / \mathrm{L}$ and higher. Previous in vitro and in vivo studies indicated that $\mathrm{ABX}$ enhanced GCase activity at concentrations of $0.3-30 \mu \mathrm{mol} / \mathrm{L}^{8}{ }^{10}{ }^{12}$ However, based on our results, there may be impetus to increase the $\mathrm{ABX}$ dosage to achieve a plasma concentration of $10 \mu \mathrm{mol} / \mathrm{L}$. At this concentration, cytotoxicity was not observed as demonstrated by LDH and CCK-8 assays and aggresome staining. However, the safety and efficacy of higher doses to achieve a plasma concentration of $30 \mu \mathrm{mol} / \mathrm{L}$ needs to be solved on further studies.

In our study, GCase activity was enhanced up to $9 \%-19 \%$ of the mean normal activity at $\mathrm{ABX}$ dose of $27 \mathrm{mg} / \mathrm{kg} /$ day, which was significantly lower than that reported by Narita et al, where GCase activity was enhanced up to $40 \%-100 \%$ of the normal activity at $\mathrm{ABX}$ dose of $25 \mathrm{mg} / \mathrm{kg} /$ day. ${ }^{10}$ One explanation for this discrepancy might be the variability in the PK characteristics among the subjects in our study (figure 5). ABX is metabolised by CYP3A4, and drug-drug interactions between $\mathrm{ABX}$ and CYP3A4 inducers or inhibitors can affect $\mathrm{ABX}$ concentration and subsequently affect GCase activity. Several antiepileptic drugs, such as topiramate and carbamazepine (CYP3A4 inducers) and divalproate sodium (CYP3A4 inhibitor) can significantly affect $\mathrm{ABX}$ concentration. In particular, in Pt2 who received carbamazepine, $\mathrm{ABX}$ concentration was persistently low $(2.33 \pm 0.43$ $\mu \mathrm{mol} / \mathrm{L}$ ) even at a dose of $27 \mathrm{mg} / \mathrm{kg} /$ day.

Impairment of saccadic eye movement is one of the characteristic findings in nGD. ${ }^{12}$ In a previous study, ${ }^{10}$ high-dose ABX was effective in improving pupillary light reflex and latency in saccadic eye movement. In our study, these parameters were not assessed in detail; however, saccadic eye movement deteriorated in two patients (online supplementary video).

Lyso-Gb1, a biomarker for the severity and progression of GD ${ }^{19}{ }^{28}$ gradually decreased in all patients until reaching a level of $7.7 \pm 1.8(6.5-10.3) \mathrm{ng} / \mathrm{mL}$, which is comparable to the normal range $(<4.8 \mathrm{ng} / \mathrm{mL}){ }^{29}$ Moreover, Lyso-Gb1 level in patients treated with $\mathrm{ABX}+\mathrm{ERT}$ was much lower than that in non-nGD and nGD patients who were treated with long-term ERT without $\mathrm{ABX}$. These data suggest evidence for the protective effects of $\mathrm{ABX}$ in GD in vivo.

Collectively, our results show that long-term treatment with high-dose ABX was generally safe. Based on the results of the mSST and K-MBI scores, seizure frequency and Lyso-Gb1 levels, long-term treatment with high-dose $\mathrm{ABX}$ abated the progression 
of neurological manifestations in GD. However, because of the wide variability in plasma $A B X$ levels among patients, assessment of drug-drug interactions (particularly with antiepileptic drugs) will be important to monitor in order to define the optimal dosage of ABX in each patient. Moreover, the clinical severity of the neurological manifestations at baseline in each patient was an important factor affecting the clinical outcome of long-term treatment with high-dose ABX+ERT. Therefore, earlier administration of $\mathrm{ABX}$, even before the progression of the neurological features (such as immediately on beginning of ERT in newly diagnosed nGD patients), might have a greater value and achieve better results. Also, rapid escalation of ABX dose might lead to faster and better outcomes. However, this may be limited by the significant respiratory mucus production and drug-drug interactions.

Recently, GBA mutations have been suggested to be associated with the development of Parkinson's disease. ${ }^{30}$ Therefore, the promising results of high-dose $\mathrm{ABX}$ treatment in nGD patients suggest that high-dose $\mathrm{ABX}$ might be a potential pharmacological therapy for more common neurodegenerative conditions. Our study showed improvement in four patients and supports larger scale studies to better define the dosing parameters for wider spread application in nGD.

\section{Author affiliations}

'Department of Pediatrics, Gangneung Asan Hospital, Gangneung, The Republic of Korea

${ }^{2}$ Department of Pediatrics, Asan Medical Center Children's Hospital, College of Medicine University of Ulsan, Seoul, The Republic of Korea

${ }^{3}$ Asan Institute for Life Sciences, Asan Medical Center, College of Medicine University of Ulsan, Seoul, The Republic of Korea

${ }^{4}$ Department of Laboratory Animal Medicine, College of Veterinary Medicine,

Kyungpook National University, Daegu, The Republic of Korea

${ }^{5}$ Department of Physiology, Cell and Matrix Research Institute, School of Medicine,

Kyungpook National University, Daegu, The Republic of Korea

${ }^{6}$ Department of Radiology and Research Institute of Radiology, Asan Medical Center,

College of Medicine University of Ulsan, Seoul

, The Republic of Korea

${ }^{7}$ Department of Ophthalmology, Asan Medical Center, College of Medicine University of Ulsan, Seoul, The Republic of Korea

${ }^{8}$ Department of Psychiatry, Asan Medical Center, College of Medicine University of Ulsan, Seoul, The Republic of Korea

${ }^{9}$ Department of Clinical Pharmacology and Therapeutics, Asan Medical Center,

College of Medicine University of Ulsan, Seoul, The Republic of Korea

${ }^{10}$ Department of Pediatrics, Division of Blood and Marrow Transplantation, University

of Minnesota Medical Center, Minneapolis, Minnesota, USA

${ }^{11}$ Centogene AG, Rostock, Germany

${ }^{12}$ Albrecht-Kossel-Institute for Neuroregeneration, Medical University of Rostock, Rostock, Germany

${ }^{13}$ The Hebrew University Hadassah Medical School, Jerusalem, Israel

${ }^{14}$ Medical Genetics Center, Asan Medical Center, College of Medicine University of

Ulsan, Seoul, The Republic of Korea

Acknowledgements We deeply appreciate the patients and their families for participating in this study. We acknowledge Professor Kousaku Ohno, Tottori University Faculty of Medicine, Yonago, Japan for his grateful consultation.

Contributors BHL, HKJ, J-SB, AR, AZ and H-WY contributed to designing the study. Y-MK, M-SY, GHS, AO, HMY, HTL, H-WK, T-SK, BHL and HMY were the clinicians who conducted all clinical and radiological examinations. S-HH, T-SK, H-SL, CC and AR did the laboratory experiments. BHL, Y-MK, M-SY, HKJ, J-SB, H-WY, HTL, MJO, JT, AR, AZ and HMY analysed the data. Y-MK, M-SY, S-HH and BHL drafted the manuscript and HKJ, MJO, JT, CC, AR, AZ revised the manuscript. All authors were involved in analysing and interpreting the data. All authors read and approved the final manuscript.

Funding This research was supported in part by the Bio \& Medical Technology Development Program of the National Research Foundation (NRF) funded by the Korean government (NRF-2015K1A4A3046807, NRF-2016M3A9B4915706 and NRF-2018M3A9H1078335) and by ISU ABXIS, Gyeonggi-do, Korea.

Competing interests None declared.

Patient consent for publication Parental/guardian consent obtained.
Ethics approval The study was approved by Institutional Review Board, Asan Medical Center, Seoul, Korea and the Ministry of Food and Drug Safety, Korea.

Provenance and peer review Not commissioned; externally peer reviewed.

Data availability statement All data relevant to the study are included in the article or uploaded as supplementary information.

Open access This is an open access article distributed in accordance with the Creative Commons Attribution Non Commercial (CC BY-NC 4.0) license, which permits others to distribute, remix, adapt, build upon this work non-commercially, and license their derivative works on different terms, provided the original work is properly cited, appropriate credit is given, any changes made indicated, and the use is non-commercial. See: http://creativecommons.org/licenses/by-nc/4.0/.

\section{ORCID iD}

Han-Wook Yoo http://orcid.org/0000-0001-9709-2631

\section{REFERENCES}

1 Tylki-Szymańska A, Vellodi A, El-Beshlawy A, Cole JA, Kolodny E. Neuronopathic Gaucher disease: demographic and clinical features of 131 patients enrolled in the International collaborative Gaucher group neurological outcomes Subregistry. J Inherit Metab Dis 2010;33:339-46.

2 Roshan Lal T, Sidransky E. The spectrum of neurological manifestations associated with Gaucher disease. Diseases 2017;5. doi:10.3390/diseases5010010

3 El-Beshlawy A, Tylki-Szymanska A, Vellodi A, Belmatoug N, Grabowski GA, Kolodny EH, Batista JL, Cox GF, Mistry PK, hematological L-term. Long-Term hematological, visceral, and growth outcomes in children with Gaucher disease type 3 treated with imiglucerase in the International collaborative Gaucher group Gaucher registry. Mol Genet Metab 2017;120:47-56

4 Sechi A, Deroma L, Dardis A, Ciana G, Bertin N, Concolino D, Linari S, Perria C, Bembi B. Long term effects of enzyme replacement therapy in an Italian cohort of type 3 Gaucher patients. Mol Genet Metab 2014:113:213-8.

5 Lee N-C, Chien Y-H, Wong S-L, Sheen J-M, Tsai F-J, Peng S-F, Leung JH, Chao M-C, Shun C-T, Hwu W-L. Outcome of early-treated type III Gaucher disease patients. Blood Cells, Molecules, and Diseases 2014;53:105-9.

6 . Clinicaltrials.Gov. Available: https://clinicaltrials.gov/ct2/show/NCT02843035? cond= Gaucher+Disease\%2C+Type+3\&rank=2 [Accessed Oct 2018]

7 Bendikov-Bar I, Maor G, Filocamo M, Horowitz M. Ambroxol as a pharmacological chaperone for mutant glucocerebrosidase. Blood Cells, Molecules, and Diseases 2013;50:141-5.

8 Maegawa GHB, Tropak MB, Buttner JD, Rigat BA, Fuller M, Pandit D, Tang L, Kornhaber GJ, Hamuro Y, Clarke JTR, Mahuran DJ. Identification and characterization of ambroxol as an enzyme enhancement agent for Gaucher disease. J. Biol. Chem. 2009;284:23502-16.

9 Revel-Vilk S, Szer J, Mehta A, Zimran A. How we manage Gaucher disease in the era of choices. Br J Haematol 2018:182:467-80

10 Narita A, Shirai K, Itamura S, Matsuda A, Ishihara A, Matsushita K, Fukuda C, Kubota N, Takayama R, Shigematsu H, Hayashi A, Kumada T, Yuge K, Watanabe Y, Kosugi S, Nishida H, Kimura Y, Endo Y, Higaki K, Nanba E, Nishimura Y, Tamasaki A, Togawa M, Saito Y, Maegaki Y, Ohno K, Suzuki Y. Ambroxol chaperone therapy for neuronopathic Gaucher disease: a pilot study. Ann Clin Trans/ Neurol 2016;3:200-15.

11 Horowitz M, Wilder S, Horowitz Z, Reiner O, Gelbart T, Beutler E. The human glucocerebrosidase gene and pseudogene: structure and evolution. Genomics 1989:4:87-96.

12 Luan Z, Li L, Higaki K, Nanba E, Suzuki Y, Ohno K. The chaperone activity and toxicity of ambroxol on Gaucher cells and normal mice. Brain and Development 2013:35:317-22.

13 Migdalska-Richards A, Daly L, Bezard E, Schapira AHV, Nanba E, Suzuki Y, Ohno K. Ambroxol effects in glucocerebrosidase and $\alpha$-synuclein transgenic mice. Ann Neurol 2016;80:766-75

14 Migdalska-Richards A, Ko WKD, Li Q, Bezard E, Schapira AHV. Oral ambroxol increases brain glucocerebrosidase activity in a nonhuman primate. Synapse 2017;71.

15 Pawlinski L, Malecki MT, Kiec-Wilk B. The additive effect on the antiepileptic treatment of ambroxol in type 3 Gaucher patient. the early observation. Blood Cells, Molecules, and Diseases 2018:68:192-3.

16 Wong K, Sidransky E, Verma A, Mixon T, Sandberg GD, Wakefield LK, Morrison A, Lwin A, Colegial C, Allman JM, Schiffmann R. Neuropathology provides clues to the pathophysiology of Gaucher disease. Mol Genet Metab 2004;82:192-207.

17 Razek AAKA, Abdalla A, Gaber NA, Fathy A, Megahed A, Barakat T, Latif Alsayed MA. Proton MR spectroscopy of the brain in children with neuronopathic Gaucher's disease. Eur Radiol 2013;23:3005-11.

18 Burrow TA, Sun Y, Prada CE, Bailey L, Zhang W, Brewer A, Wu SW, Setchell KDR, Witte D, Cohen MB, Grabowski GA. Cns, lung, and lymph node involvement in Gaucher disease type 3 after 11 years of therapy: clinical, histopathologic, and biochemica findings. Mol Genet Metab 2015;114:233-41.

19 Rolfs A, Giese A-K, Grittner U, Mascher D, Elstein D, Zimran A, Böttcher T, Lukas J, Hübner R, Gölnitz U, Röhle A, Dudesek A, Meyer W, Wittstock M, Mascher H. Glucosylsphingosine is a highly sensitive and specific biomarker for primary diagnostic 
and follow-up monitoring in Gaucher disease in a non-Jewish, Caucasian cohort of Gaucher disease patients. PLoS One 2013;8:e79732.

20 Dekker N, van Dussen L, Hollak CEM, Overkleeft H, Scheij S, Ghauharali K, van Breemen MJ, Ferraz MJ, Groener JEM, Maas M, Wijburg FA, Speijer D, Tylki-Szymanska A, Mistry PK, Boot RG, Aerts JM. Elevated plasma glucosylsphingosine in Gaucher disease: relation to phenotype, storage cell markers, and therapeutic response. Blood 2011;118:e118-27.

21 Mirzaian M, Wisse P, Ferraz MJ, Gold H, Donker-Koopman WE, Verhoek M, Overkleeft HS, Boot RG, Kramer G, Dekker N, Aerts JMFG. Mass spectrometric quantification of glucosylsphingosine in plasma and urine of type 1 Gaucher patients using an isotope standard. Blood Cells, Molecules, and Diseases 2015;54:307-14.

$22 \mathrm{Kim} \mathrm{H}$, Yoo J-Y, Han SB, Lee HJ, Lee KR. Determination of ambroxol in human plasma using LC-MS/MS. J Pharm Biomed Anal 2003;32:209-16.

23 Laoag-Fernandez JB, Fernandez AM, Maruo T. Antenatal use of ambroxol for the prevention of infant respiratory distress syndrome. J Obstet Gynaecol Res 2000;26:307-12.

24 Li Q, Yao G, Zhu X. High-Dose ambroxol reduces pulmonary complications in patients with acute cervical spinal cord injury after surgery. Neurocrit Care 2012;16:267-72.
25 Ishiguro N, Senda C, Kishimoto W, Sakai K, Funae Y, Igarashi T. Identification of CYP3A4 as the predominant isoform responsible for the metabolism of ambroxol in human liver microsomes. Xenobiotica 2000;30:71-80.

26 Schueler UH, Kolter T, Kaneski CR, Zirzow GC, Sandhoff K, Brady RO. Correlation between enzyme activity and substrate storage in a cell culture model system for Gaucher disease. J Inherit Metab Dis 2004;27:649-58.

27 Nair A, Jacob S. A simple practice guide for dose conversion between animals and human. J Basic Clin Pharm 2016;7:27-31.

28 Arkadir D, Dinur T, Revel-Vilk S, Becker Cohen M, Cozma C, Hovakimyan M, Eichler S, Rolfs A, Zimran A. Glucosylsphingosine is a reliable response biomarker in Gaucher disease. Am J Hematol 2018;93:E140-E142.

29 Cozma C, Couchon EC, Giese A-K, lurascu M, Rolfs A. Quantification of glucosylshingosine (lyso-Gb1) for the diagnosis and monitoring of Gaucher disease. Mol Genet Metab 2018;123:S35.

30 Aharon-Peretz J, Rosenbaum H, Gershoni-Baruch R. Mutations in the glucocerebrosidase gene and Parkinson's disease in Ashkenazi Jews. N Engl I Med 2004;351:1972-7 